\title{
Drug-Resistant Polymorphisms and Copy Numbers in Plasmodium falciparum, Mozambique, 2015
}

\author{
Himanshu Gupta, Eusebio Macete, Helder Bulo, Crizolgo Salvador, Marian Warsame, Eva Carvalho, \\ Didier Ménard, Pascal Ringwald, Quique Bassat, Sonia Enosse, ${ }^{1}$ Alfredo Mayor ${ }^{1}$
}

One of the fundamental steps toward malaria control is the use of antimalarial drugs. The success of antimalarial treatment can be affected by the presence of drug-resistant populations of Plasmodium falciparum. To assess resistance, we used molecular methods to examine $351 P$. falciparum isolates collected from 4 sentinel sites in Mozambique for K13, pfmdr1, pfcrt, and pfdhps polymorphisms and for plasmepsin2 (pfpm2) and pfmdr1 copy numbers. We found multiple copies of pfpm 2 in $1.1 \%$ of isolates. All isolates carried K13 wild-type alleles (3D7-like), except 4 novel polymorphisms (Leu619Leu, Phe656lle, Val666Val, Gly690Gly). Prevalence of isolates with pfcrt mutant (K76T) allele was low $(2.3 \%)$. Prevalence of isolates with pfdhps mutant alleles (A437G and K540E) was $>80 \%$, indicating persistence of sulfadoxine/pyrimethamine resistance; however, markers of artemisinin were absent, and markers of piperaquine resistance were low. Piperaquine resistance isolates may spread in Mozambique as dihydroartemisinin/piperaquine drug pressure increases.

$\mathrm{D}$ uring the past decade, malaria control strategies have substantially reduced the malaria burden worldwide; several countries are advancing toward malaria elimination $(1,2)$. A fundamental pillar for contributing to the reduction of the malaria burden has been artemisinin-based combination therapy. Unfortunately, the effectiveness of

Author affiliations: ISGlobal, Barcelona Institute for Global Health, Hospital Clínic, Universitat de Barcelona, Barcelona, Spain (H. Gupta, Q. Bassat, A. Mayor); Centro de Investigação em Saúde de Manhiça, Maputo, Mozambique (E. Macete, H. Bulo, Q. Bassat, A. Mayor); Instituto Nacional de Saúde, Ministério da Saúde, Maputo (C. Salvador, S. Enosse); World Health Organization Global Malaria Programme, Geneva, Switzerland (M. Warsame, P. Ringwald); World Health Organization, Maputo (E. Carvalho); Malaria Molecular 16 Epidemiology Unit, Institut Pasteur du Cambodge, Phnom Penh, Cambodia (D. Ménard); Institut Pasteur, Paris, France (D. Ménard); ICREA, Barcelona (Q. Bassat); Pediatrics Department, Hospital Sant Joan de Déu (University of Barcelona), Barcelona, Spain (Q. Bassat)

DOI: https://doi.org/10.3201/eid2401.170864 antimalarial drugs used for malaria treatment and chemoprevention during pregnancy has been threatened by the emergence of drug-resistant parasite populations (2-5).

The emergence of artemisinin resistance in Plasmodium falciparum, with reduced in vivo susceptibility to artesunate, was reported in Southeast Asia $(3,6)$. Detectable polymorphisms in the Kelch 13 (K13) propeller domain in P. falciparum associated with artemisinin resistance have subsequently provided an additional tool for monitoring resistance to antimalarial drugs $(7,8)$. In Cambodia, polymorphisms in the $K 13$ propeller domain (mainly Y493H, R539T, I543T, and C580Y) were associated with in vitro prolonged parasite survival rates and in vivo delayed parasite clearance rates $(8,9)$. Recently, plasmepsin 2 (pfpm2) copy number and pfcrt $\mathrm{C} 101 \mathrm{~F}$ polymorphism have been associated with piperaquine resistance (10-12). In addition, increased pfmdrl copies have been associated with resistance to mefloquine (in vivo, in vitro, or both) and partially to lumefantrine (13-18). Specific point polymorphisms (at codons 86, $184,1034,1042$, and 1246) of the $p f m d r 1$ gene have also been linked to resistance to antimalarial drugs $(19,20)$. In field isolates tested in vitro as well as in laboratory lines, N86Y polymorphism was associated with chloroquine resistance (21). Further, polymorphisms in the pfcrt gene have also been shown to affect parasite susceptibility to chloroquine (22), amodiaquine $(23,24)$, and artemether/ lumefantrine (25). Recently, a nonsynonymous polymorphism in the pfcrt gene was shown to be prevalent in the genetic background of K13 mutant artemisinin-resistant isolates (26). In addition, polymorphisms in pfdhfr and pfdhps genes, specifically the quintuple mutant, including the pfdhfr substitutions N51I, C59R, and S108N, as well as the pfdhps substitutions A437G and K540E, have been associated with a failure of sulfadoxine/pyrimethamine treatment against uncomplicated $P$. falciparum malaria (27). In Africa, the pfdhps K540E polymorphism has been considered a useful epidemiologic marker of the quintuple mutations (28).

\footnotetext{
${ }^{1}$ These authors contributed equally to this article.
} 
The development of drug resistance could be influenced by multiple factors such as polymorphism rate, fitness costs, overall parasite load, strength of drug selection, treatment compliance, transmission intensity, host immunity, and erythrocyte disorders (29-31). Naturally acquired immunity plays a major role in the emergence and clearance of artemisinin-resistant parasites (32). Because of increasing concern over the effectiveness of the nationally recommended antimalarial drugs, the Mozambique Ministry of Health has made several changes in antimalarial drug policy. In 2002, chloroquine monotherapy was replaced with sulfadoxine/pyrimethamine/amodiaquine as the first line of treatment against uncomplicated malaria (33); 2 years later, this combination was replaced with artesunate/sulfadoxine/pyrimethamine (33). In 2008, artemether/lumefantrine was introduced to replace artesunate/ sulfadoxine/pyrimethamine (34). Molecular markers for antimalarial drug resistance have been considered useful for confirming parasite resistance, a major factor causing treatment failure. To determine whether parasites carrying these polymorphisms or gene amplifications exist in Mozambique, we conducted molecular surveillance targeting K13, pfmdrl, pfcrt, and pfdhps polymorphisms and pfpm 2 and $p f m d r 1$ copy numbers in field isolates collected from 4 sentinel sites.

\section{Materials and Methods}

\section{Study Sites and Population}

We performed a descriptive observational study on blood samples collected before artemether/lumefantrine treatment (on day 0) in 2015 from 352 symptomatic children at 4 sentinel sites in Mozambique (Figure 1): 1) Hospital Rural de Montepuez in Cabo Delgado Province (northern region), 2) Centro de Saúde de Dondo in Sofala Province (central region), 3) Hospital Provincial de Moatize in Tete Province (central region), and 4) Hospital Rural de Chokwe in Gaza Province (southern region). In Mozambique, transmission usually peaks during the rainy season (November-April). Transmission intensity in southern Mozambique is generally low, although areas of high transmission may still occur (35). To determine molecular markers of drug resistance, we analyzed samples collected during a clinical trial conducted in 2015 (registration no. ACTRN12616001680459); the trial aimed to assess the efficacy and safety of artemether/ lumefantrine for treatment of uncomplicated $P$. falciparum malaria in children $<5$ years of age. The National Mozambican Ethical Review Committee (Mozambique) and Hospital Clínic (Barcelona, Spain) ethics review committees approved the study, and signed written informed consent was obtained from all participants' guardian or parent.

\section{Molecular Procedures}

We extracted DNA from half of a $50-\mu \mathrm{L}$ dried blood drop on Whatman 3-mm filter paper by using a QIAamp DNA Mini kit (QIAGEN, Hilden, Germany) according to the manufacturer's instructions. We used an ABI PRISM 7500 HT Real-Time System (Applied Biosystems, Foster City, CA, USA) to amplify purified parasite DNA templates, following a previously described method $(36,37)$. A standard curve was prepared from an in vitro culture of $3 \mathrm{D} 7$ strain containing known numbers of ring-infected erythrocytes.

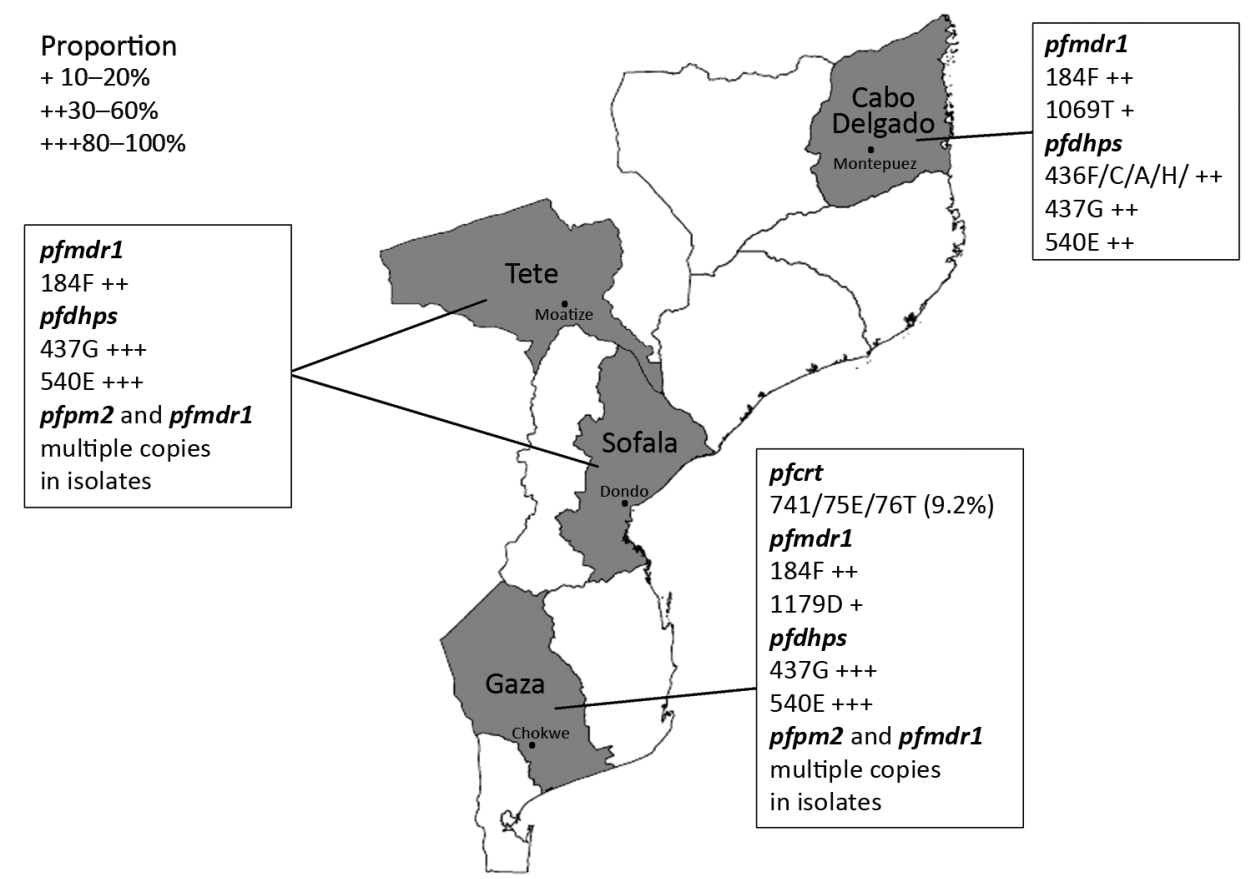

Figure 1. Location of sampling sites and distribution of resistance markers of Plasmodium falciparum in Mozambique, 2015. 
The standard curve was run in triplicate for each test with 5 serially diluted points. Parasitemia in the clinical samples was quantified by extrapolation against the standard curve.

To assess polymorphisms in the K13, pfcrt, pfmdrl, and pfdhps genes, we amplified purified DNA templates by using a 2720 Thermal Cycler (Applied Biosystems), following protocols described for K13 PCR (38) and pfcrt PCR (35). To genotype polymorphisms in $p f m d r l$ and pfdhps genes, we designed new assays by using Sanger sequencing and restriction fragment length polymorphisms (online Technical Appendix, https://wwwnc.cdc.gov/EID/ article/24/1/17-0864-Techapp1.pdf). A total of 6 positive controls with known $K 13$ alleles, provided by the Institut Pasteur in Cambodia, and 4 parasite lines (3D7, 7G8, $\operatorname{Dd} 2$, and V1/S) with known $p f c r t$ and $p f m d r 1$ alleles, available in the laboratory, were also processed, amplified, and sequenced at the same time as the studied samples (PCR characteristics in online Technical Appendix Table). To determine the detection limit of Sanger sequencing, we used artificially mixed DNA samples of $P$. falciparum laboratory strains containing various known proportions of wild- and mutant-type alleles of $p f c r t$ (K76T) and $p f m d r 1$ (Y184F and S1034C) genes. To estimate polymorphism frequency, we considered isolates with mixed alleles to be mutated.

We assessed copy numbers of $p f p m 2$ and $p f m d r 1$ genes as described elsewhere (11) with minor changes (online Technical Appendix) by using quantitative PCR (qPCR). We performed amplification in $20-\mu \mathrm{L}$ reaction mixtures for $p f p m 2, p f m d r 1$, and $p f \beta$-tubulin genes, separately. We used the $p f \beta$-tubulin gene as an endogenous control. All samples with estimated copy numbers $>1.5$ were defined as containing multiple copies and repeated for confirmation. The estimated copy numbers were the average of the copy number of each clone in the isolate.

\section{Data Analyses}

We calculated the proportion of the mutant alleles and isolates with multiple copies of pfpm 2 and $p f m d r 1$ genes on the basis of the number of samples with wild- and mutant-type alleles as well as isolates with single and multiple copies of the gene from P. falciparum isolates from each study site. To compare continuous data and categorical data between sites, respectively, we performed analyses of variance and $\chi^{2}$ tests. We defined statistical significance as $p<0.05$.

\section{Results}

\section{Demographics and $P$. falciparum Infection}

Among the 352 blood samples collected before artemether/lumefantrine treatment (on day 0) during 2015, and followed up as part of the clinical trial, 351 (99.7\%) were $P$. falciparum-infection positive according to $18 \mathrm{Sr}$ RNA qPCR. The mean ( \pm SD) parasitemia (by qPCR) was $100,229 \pm 325,214$ parasites $/ \mu \mathrm{L}$. Among participants, 159 $(45.2 \%)$ were female, mean $( \pm \mathrm{SD})$ age was $2.8 \pm 1.3 \mathrm{y}$, mean body temperature was $38.1 \pm 1.1^{\circ} \mathrm{C}$, and mean hemoglobin level was $9.2 \pm 1.9 \mathrm{~g} / \mathrm{dL}$. We also compared demographic data and parasite densities according to study site (Table 1). Efficacy of artemether/lumefantrine in the in vivo study was high, and for nearly all patients (349 [99.4\%] of 351), parasitemia reverted to 0 in the first 3 days; however, for 2 patients, parasites were still detectable by microscopy: 1 from Moatize (514 parasites $/ \mu \mathrm{L}$ ) and 1 from Chokwe (3,763 parasites/ $\mu \mathrm{L})$. PCRs targeting $m s p 1$, $m s p 2$, and glurp genes were used to differentiate recrudescence (same parasite strain) and reinfection (different parasite strain). We noted recrudescence of $P$. falciparum infections for 5 children ( 1 in Chokwe, 3 in Moatize, and 1 in Montepuez) on days 21 and 28 after artemether/lumefantrine administration and reinfection for 7 children ( 3 in Moatize and 4 in Montepuez); 3 were reinfected on day 21 and 4 on day 28 (39).

The polymorphism analyses of K13,pfmdrl, pfcrt, and pfdhps genes were successful for $98.3 \%$ to $100 \%$ isolates. Because no amplifications were noticed in negative controls (with water and human genomic DNA), PCR assays were specific to P. falciparum genomic DNA only.

\section{Detection Limit of Mixed Samples by Sanger Sequencing}

We identified "A" alleles of pfcrt (K76T) and pfmdr1 (Y184F) codons in artificially mixed samples by using Sanger sequencing when the proportion of target DNA was $\geq 10 \%$. However, we identified " $\mathrm{C}$ " and " $\mathrm{T}$ " alleles of $p f c r t$ (K76T) and $p f m d r 1$ (Y184F) polymorphisms, respectively, in mixed samples when their proportion was $\geq 20 \%$ (online Technical Appendix Figure 1). For pfmdr1 (S1034C) polymorphism, the minor allele was detected when its proportion was $\geq 20 \%$ in a mixed sample (online Technical

\begin{tabular}{|c|c|c|c|c|c|}
\hline Characteristic & Montepuez, n = 87 & Dondo, $\mathrm{n}=88$ & Moatize, $n=89$ & Chokwe, $\mathrm{n}=88$ & $p$ value \\
\hline Female, no. (\%) & $36(41.4)$ & $40(45.5)$ & $41(46.1)$ & $42(47.7)$ & 0.63 \\
\hline Age, $y$, mean $\pm S D$ & $2.4 \pm 1.1$ & $2.7 \pm 1.1$ & $2.7 \pm 1.1$ & $3.1 \pm 1.1$ & 0.0002 \\
\hline Temperature, ${ }^{\circ} \mathrm{C}$, mean $\pm \mathrm{SD}$ & $37.9 \pm 0.9$ & $38.5 \pm 1.1$ & $38.1 \pm 1.0$ & $37.9 \pm 1.5$ & 0.0043 \\
\hline $\begin{array}{l}\text { Parasite density, parasites } / \mu \mathrm{L} \text {, } \\
\text { mean } \pm \mathrm{SD}^{*}\end{array}$ & $1.2 \times 10^{5} \pm 1.3 \times 10^{5}$ & $3.7 \times 10^{4} \pm 4.4 \times 10^{4}$ & $1.2 \times 10^{5} \pm 6.1 \times 10^{5}$ & $1.2 \times 10^{5} \pm 1.8 \times 10^{5}$ & $<0.0001$ \\
\hline Hemoglobin, g/dL, mean \pm SD & $8.9 \pm 2.2$ & $8.7 \pm 1.8$ & $9.8 \pm 1.7$ & $9.2 \pm 2.0$ & 0.0018 \\
\hline
\end{tabular}


Appendix Figure 1, panel C). For positive controls, we used several parasite lines with known K13, pfmdrl, and $p f c r t$ alleles. As expected, sequencing analysis of all positive controls revealed wild- and mutant-type alleles of $K 13$, pfmdrl, and pfcrt polymorphisms.

\section{Copy Numbers for pfpm 2 and pfmdr1}

We successfully analyzed 351 (100\%) samples for copy number variation in the $p f p m 2$ and $p f m d r 1$ genes. PCR efficiencies were $98.4 \%$ for $p f p m 2,97.2 \%$ for $p f m d r 1$, and $99.2 \%$ for $p f \beta$-tubulin genes. As expected, the estimated pfpm 2 and pfmdr 1 copy numbers for the positive controls were $3-4$ copies. The estimated mean (interquartile range) copy numbers were $3.51(3.37-3.62)$ for pfpm 2 and 3.62 (3.51-3.79) for $p f m d r l$ positive controls. When we used a copy number threshold of 1.5 to define multiple copies, only $4(1.1 \%)$ and $5(1.4 \%)$ of the 351 isolates had multiple copies of $p f p m 2$ and $p f m d r 1$, respectively (Table 2; Figure 2). The range of estimated pfpm 2 copy numbers was $0.59-1.79$ and of $p f m d r l$ was $0.58-1.88$. The copy number of $p f p m 2$ and $p f m d r 1$ genes did not significantly differ between isolates from different sites. The proportion of isolates with multiple copies of the $p f p m 2$ gene was the highest at Chokwe (2 [2.3\%] of 87). Only $1(1.1 \%)$ of 88 samples from Dondo had multiple copies of pfpm 2 and pfmdrl genes.

\section{K13 Polymorphisms}

We successfully achieved K13 PCR and sequencing for all 351 isolates. None of the isolates analyzed contained the polymorphisms most frequently found in isolates from Cambodia (8). However, we observed 4 novel polymorphisms at nt 1725147 (codon $619 ; 0.28 \%$ [1/351]); 1725032 (codon 656; 0.28\% [1/351]); 1725000 (codon 666; 0.57\% [2/351]); and 1724927 (codon 690; $0.85 \%$ [3/351]) of the $K 13$ gene. All polymorphisms were synonymous except for 1 at codon 656 , which led to a change from phenylalanine to isoleucine. When we compared frequencies of new polymorphisms between sites, we found no significant differences. We also observed the polymorphism Cys469Cys, previously described in P. falciparum field isolates from Ghana (40), in $3(0.85 \%)$ of the 351 isolates. Isolates from patients with parasitemia on day 3 and recrudescence contained wild-type $K 13$ gene polymorphisms.

\section{pfcrt Polymorphisms}

We successfully amplified all 351 samples for pfcrt and sequenced the amplification products; mutant alleles were found at codons M74I, N75E, and K76T only in $8(2.3 \%)$ samples. The mutant alleles (M74I, N75E, and K76T) were present only in isolates collected from Chokwe (8 [9.2\%] of 87). When we compared frequencies of mutant alleles between sites, the difference was significant $(p<0.0001)$. In the studied isolates, the mutant (F) allele at codon 101 was absent. Isolates from patients with parasitemia on day 3 and recrudescence contained wild-type pfcrt gene polymorphisms.

\section{pfmdr1 Polymorphisms}

We successfully amplified and sequenced $p f m d r 1 \mathrm{fl}$ for 351 (100\%) samples and pfmdr1_f2 fragments for 350 (99.7\%) samples. We identified 15 polymorphisms all across the pfmdrl gene, including $5(33.3 \%)$ with nonsynonymous polymorphisms and $10(66.7 \%)$ with synonymous polymorphisms. Among nonsynonymous polymorphisms, 3 (T1192A, F1194S, and Y1197N) were newly identified and 2 (N86Y and Y184F) had been previously reported (41). Among synonymous polymorphisms, 7 (L1030L, D1061D, D1127D, S1137S, L1174L, D1179D, and N1189N) were newly identified and 3 (G102G, G182G, and T1069T) had been previously reported (41). Among the 351 isolates, we found $11(3.1 \%) \mathrm{N} 86 \mathrm{Y}$ and $164(46.7 \%) \mathrm{Y} 184 \mathrm{~F}$ mutant alleles (Table 3). All newly identified nonsynonymous mutant alleles were present only once, except for Y1197N, which was found twice $(0.6 \%$ [2/350]). The frequency of polymorphisms (N86Y and D1179D) differed significantly between isolates from the 4 sites (Table 3 ). The proportion of N86Y and D1179D polymorphisms was highest in isolates from Chokwe. We observed none of the other most frequent polymorphisms (S1034C, N1042D, and D1246Y) of the $p f m d r 1$ gene among the analyzed samples. Isolates from patients with parasitemia on day 3 and recrudescence contained wild-type $p f m d r l$ gene polymorphisms.

\section{pfdhps Polymorphisms}

Polymorphism analysis by PCR followed by sequencing for S436F and A437G polymorphisms was successful for 345 (98.3\%) samples and analysis by PCR-restricted fragment length polymorphism for K540E polymorphism for $348(99.1 \%)$ samples. Among all isolates, 10 (2.9\%) of 345

\begin{tabular}{|c|c|c|c|c|c|c|c|c|}
\hline \multirow[b]{3}{*}{ Site } & \multicolumn{4}{|c|}{ pfpm2 } & \multicolumn{4}{|c|}{ pfmdr1 } \\
\hline & \multicolumn{3}{|c|}{ No. (\%) } & \multirow[b]{2}{*}{ Mean \pm SD } & \multicolumn{3}{|c|}{ No. (\%) } & \multirow[b]{2}{*}{ Mean \pm SD } \\
\hline & $\leq 1.2$ & $1.2-1.5$ & $\geq 1.5$ & & $\leq 1.2$ & $1.2-1.5$ & $\geq 1.5$ & \\
\hline Montepuez, $\mathrm{n}=87$ & $82(94.3)$ & $5(5.7)$ & 0 & $0.85 \pm 0.2$ & $87(100.0)$ & 0 & 0 & $0.93 \pm 0.1$ \\
\hline Dondo, $n=88$ & $66(75.0)$ & $21(23.9)$ & $1(1.1)$ & $1.02 \pm 0.2$ & $68(77.3)$ & $18(20.4)$ & $2(2.3)$ & $0.99 \pm 0.3$ \\
\hline Moatize, $n=89$ & 73 (82.0) & 15 (16.9) & $1(1.1)$ & $1.01 \pm 0.2$ & 81 (91.0) & $7(7.9)$ & $1(1.1)$ & $0.99 \pm 0.2$ \\
\hline Chokwe, $n=87$ & 77 (88.5) & $8(9.2)$ & $2(2.3)$ & $0.94 \pm 0.2$ & $70(80.5)$ & $15(17.2)$ & $2(2.3)$ & $0.98 \pm 0.2$ \\
\hline
\end{tabular}




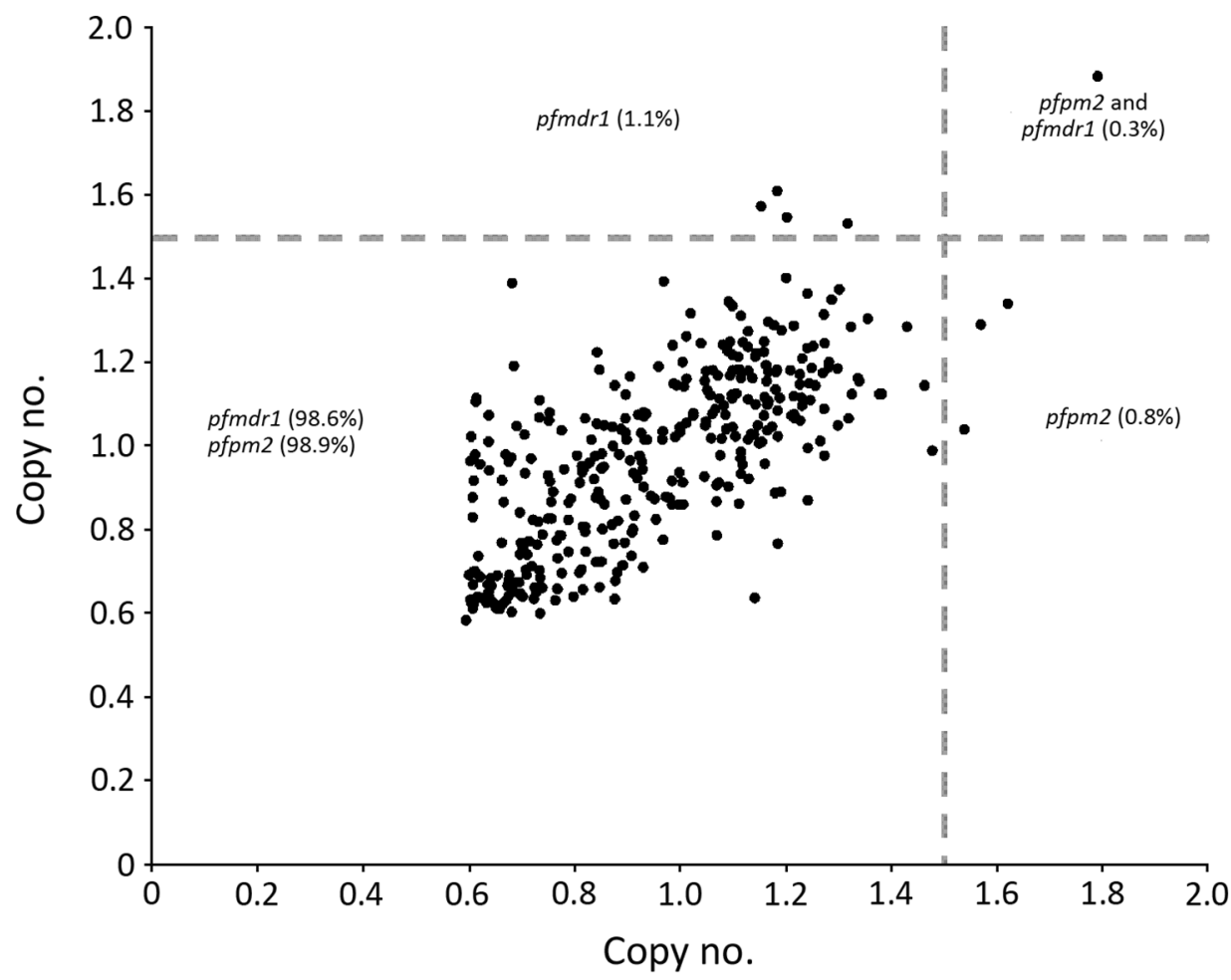

Figure 2. pfpm2 and pfmdr1 copy numbers of Plasmodium falciparum isolates from 4 sentinel sites, Mozambique, 2015. Multiple copies of pfpm2 and pfmdr1 genes have been associated with resistance to piperaquine and mefloquine, respectively. contained S436F, 289 (83.8\%) of 345 contained A437G, and $286(82.2 \%)$ of 348 contained K540E mutant alleles. At codon 436, we also found 3 mutant alleles: S436C $(0.9 \%)$, S436A (4.9\%), and S436H (0.6\%). When we compared frequencies of 3 single-nucleotide polymorphisms at different sites, we noted significant differences (Table 4). The proportion of isolates with A437G and K540E polymorphisms was the highest at Moatize, and the proportion with S436F, S436C, S436A, and S436H alleles was highest at Montepuez.

\section{Discussion}

We provide evidence for the presence of multiple copies of pfpm 2 in $4(1.1 \%)$ of $351 P$. falciparum isolates circulating in southern Mozambique despite the absence of piperaquine drug pressure. Thus, with adequate drug pressure, isolates resistant to piperaquine may spread in Mozambique, as occurred in Southeast Asia $(10,42,43)$. In selected areas of Cambodia in 2008, piperaquine was introduced as a partner drug of artemisinin (44). Soon after its introduction, as early as 2010, piperaquine resistance in western Cambodia emerged at an alarming rate (45). Subsequent reports confirmed a rapid increase in failure of dihydroartemisinin/piperaquine in other parts of Cambodia $(42,46,47)$. The most frequent $K 13$ mutants associated with artemisinin resistance were absent in the isolates from Mozambique. We also determined that prevalence of pfcrt (K76T) and pfmdrl (N86Y) markers of resistance are low, supporting previous evidence for the return of parasites carrying pfcrt wild-type alleles in Mozambique (35), in contrast to persistence of pfdhps (A437G [83.8\%]) and K540E [82.2\%]) polymorphisms, markers of sulfadoxine/pyrimethamine resistance (34). The well-characterized polymorphism in pfmdr1 (Y184F [46.7\%]) was also prevalent in Mozambique.

We found very low prevalence $(<1 \%)$ for 4 new polymorphisms (Leu619Leu, Phe656Ile, Val666Val, and Gly690 Gly) in the $K 13$ gene of $P$. falciparum isolates from Mozambique. All polymorphisms except Phe656Ile were synonymous. Previously, V494I K13 nonsynonymous polymorphism has also been reported in Mozambique (48). In Africa, K13 nonsynonymous polymorphisms have also been reported at low frequencies in isolates from Cameroon, Central African Republic, Democratic Republic of the Congo, Gabon, The Gambia, Kenya, Madagascar, Malawi, Mali, Rwanda, Togo, Uganda, Zambia, and Equatorial Guinea (38,40,49-50; references 51,52 in online Technical Appendix). The association of nonsynonymous polymorphisms with delayed parasite clearance has only recently been identified in Africa (reference 52 in online Technical Appendix).

Resistance to both chloroquine and amodiaquine has been mainly associated with a single K76T mutant allele in the pfcrt gene (22-24). In our study, its prevalence in $8(2.3 \%)$ of 351 samples was significantly lower than that found in previous studies in Mozambique (33,34; 
Table 3. Distribution of Plasmodium falciparum pfmdr1 polymorphism (mutated allele) frequencies among 4 sentinel sites, Mozambique, 2015*

\begin{tabular}{|c|c|c|c|c|c|}
\hline SNP & Montepuez, no. (\%) & Chokwe, no. (\%) & Moatize, no. (\%) & Dondo, no. (\%) & $p$ value \\
\hline N86Y & $1(1.1)$ & $6(6.9)$ & 0 & $4(4.5)$ & 0.03 \\
\hline G102G & $1(1.1)$ & $2(2.3)$ & $2(2.2)$ & $1(1.1)$ & 0.88 \\
\hline G182G & $4(4.6)$ & $1(1.1)$ & $3(3.4)$ & $1(1.1)$ & 0.37 \\
\hline Y184F & $45(51.7)$ & $39(44.8)$ & $42(47.2)$ & $38(43.2)$ & 0.69 \\
\hline L1030L & 0 & 0 & $1(1.1)$ & 0 & 0.40 \\
\hline D1061D & 0 & $1(1.1)$ & 0 & 0 & 0.40 \\
\hline T1069T & $10(11.5)$ & $5(5.7)$ & $4(4.5)$ & $8(9.2)$ & 0.28 \\
\hline D1127D & $1(1.1)$ & 0 & $2(2.2)$ & 0 & 0.30 \\
\hline S1137S & $2(2.3)$ & 0 & 0 & $2(2.3)$ & 0.25 \\
\hline L1174L & $1(1.1)$ & 0 & 0 & 0 & 0.40 \\
\hline D1179D & 0 & $9(10.3)$ & $2(2.2)$ & 0 & 0.0001 \\
\hline N1189N & 0 & 0 & $1(1.1)$ & $1(1.1)$ & 0.57 \\
\hline T1192A & 0 & $1(1.1)$ & 0 & 0 & 0.40 \\
\hline F1194S & $1(1.1)$ & 0 & 0 & 0 & 0.40 \\
\hline Y1197N & $1(1.1)$ & 0 & 0 & $1(1.1)$ & 0.57 \\
\hline
\end{tabular}

reference 53 in online Technical Appendix). Our pfcrt data align with previous evidence for the return of parasites carrying pfcrt wild-type alleles in Mozambique (35) and in other countries in Africa, such as Ethiopia (reference 54 in online Technical Appendix), Malawi (reference 55 in online Technical Appendix), and Cameroon (reference 56 in online Technical Appendix). The selective disadvantage of mutant parasites in the absence of drug pressure has been proposed as the leading factor contributing to the reemergence of chloroquine-susceptible parasites (reference 57 in online Technical Appendix). Because artemether/lumefantrine has been shown to select for the wild-type $p f c r t 76 \mathrm{~K}$ allele (25), this reemergence might be accelerated because of the increased use of artemether/lumefantrine as a firstline treatment for uncomplicated malaria in Mozambique (reference 53 in online Technical Appendix).

Our study also provides evidence for the presence of few $P$. falciparum isolates with multiple copies of the pfmdrl gene (5 [1.4\%] of 351) circulating in southern Mozambique (34). Increased pfmdrl copies have been associated with resistance to mefloquine and partial resistance to lumefantrine (13-18). Our study found that prevalence of the pfmdrl N86Y mutant allele has decreased and the Y184F mutant allele has increased over time, in contrast with findings of other studies from Mozambique (34; references 55,58 in online Technical Appendix). We identified 10 new polymorphisms (L1030L, D1061D, D1127D, S1137S, L1174L, D1179D, N1189N, T1192A, F1194S, and Y1197N) that had not been previously described for the $p f m d r 1$ gene. Among the 15 polymorphisms identified in the pfmdrl gene, we observed significant differences between sites for the N86Y and D1179D polymorphisms only.

Of 351 children who had received adequate treatment with artemether/lumefantrine ( 6 doses), 2 were still positive for parasitemia on day 3 (39). These isolates contained wild-type $K 13$ gene polymorphisms. P. falciparum-positive patients for whom artemether/lumefantrine treatment failed had parasites that carried wild-type $p f c r t$ and $p f m d r 1$ polymorphisms. This observation suggests that in vivo artemether/lumefantrine resistance may be caused not only by variations in the pfcrt and $p f m d r 1$ genes but possibly by parasite selection of variations in other genes; however, drug bioavailability issues may also have contributed.

A high proportion of the $P$. falciparum isolates from Mozambique contained K540E (82.2\%) and A437G $(83.8 \%)$ mutant alleles. These mutant alleles may still not jeopardize the effectiveness of sulfadoxine/pyrimethamine for malaria prevention in Mozambique; recent findings suggest that only $>90 \%$ prevalence of a pfdhps $\mathrm{K} 540 \mathrm{E}$ polymorphism could reduce the effectiveness of intermittent preventive therapy to clear peripheral parasites and prevent new infections during pregnancy (reference 59 in online Technical Appendix). Therefore, sulfadoxine/pyrimethamine remains effective for intermittent preventive therapy during pregnancy, despite the high frequency of quintuple mutants; thus, the World Health Organization continues to recommend the use of intermittent preventive therapy to prevent malaria during pregnancy (references 60-62 in online Technical Appendix).

\begin{tabular}{|c|c|c|c|c|c|}
\hline SNP & Montepuez, no. (\%) & Chokwe, no. (\%) & Moatize, no. (\%) & Dondo, no. (\%) & $p$ value \\
\hline $\mathrm{S} 436 \mathrm{~F} / \mathrm{C} / \mathrm{A} / \mathrm{H}$ & $30(34.5)$ & $2(2.4)$ & 0 & 0 & $<0.0001$ \\
\hline A437G & $51(58.6)$ & 79 (94.1) & $82(93.2)$ & 77 (89.5) & $<0.0001$ \\
\hline K540E & $50(57.5)$ & 77 (90.6) & 83 (93.3) & 76 (87.4) & $<0.0001$ \\
\hline$A 437 G+K 540 E$ & $47(54.1)$ & 77 (91.7) & $80(90.9)$ & $76(88.4)$ & $<0.0001$ \\
\hline
\end{tabular}

${ }^{*}$ SNP, single-nucleotide polymorphism. 
However, alternative antimalarial drugs for intermittent preventive therapy during pregnancy are needed because the prevalence of the K540E polymorphism in Mozambique is close to the threshold.

In conclusion, we report that prevalence of isolates with multiple copies of $p f p m 2$ is lower than that found by previous studies in Cambodia (34.3\%) and Vietnam $(54.3 \%)(10,43)$, and we report the absence of K13 polymorphisms known to be associated with artemisinin resistance. We also report the return of parasites carrying $p f c r t$ wild-type alleles (except in Chokwe) and persistence of parasites with pfdhps mutations associated with sulfadoxine/pyrimethamine resistance in Mozambique. Sulfadoxine/pyrimethamine-resistant isolates may be maintained by the constant use of intermittent preventive therapy during pregnancy, use of drug outside of hospitals, the very common use of co-trimoxazole (as prophylaxis for HIV-infected persons), and the low fitness cost of the polymorphisms (33; references 63,64 in online Technical Appendix). In contrast, the fitness cost of the pfcrt mutant allele seems to be high, probably accounting for the return of parasites carrying $p f c r t$ wild-type alleles in Mozambique (reference 57 in online Technical Appendix). Current regional elimination efforts, as part of the G8 Malaria Elimination Initiative, may lead to more aggressive strategies involving population-wide distribution of antimalarial drugs, such as dihydroartemisinin/piperaquine, resulting in significantly increased drug pressure. Our findings might provide baseline prevalence data that enable us to directly determine the effects that increasing malaria control efforts or elimination programs will have on resistance evolution.

\section{Acknowledgments}

We thank all study participants, field workers, laboratory workers, and everyone who supported this study directly or indirectly. We also thank Silvie Huijben, Mercedes Rubio, and Nilo Ortiz de Zugasti Carrón for their useful comments on this manuscript.

We thank the World Health Organization for providing the funds for this study, as well as the Instituto de Salud Carlos III (PI13/01478 cofunded by the Fondo Europeo de Desarrollo Regional, and CES10/021-I3SNS) to A.M. A.M. is also supported by the Departament d'Universitats i Recerca de la Generalitat de Catalunya, Agència de Gestió d'Ajuts Universitaris i de Recerca (2014SGR263). H.G. has a fellowship from the Overseas Postdoctoral Fellowship program by the Science and Engineering Research Board, Department of Science \& Technology, Government of India (SB/OS/ PDF-043/2015-16). The Centro de Investigaçao em Saude de Manhica receives major core funding from the Spanish Agency for International Cooperation. ISGlobal is a member of the CERCA Programme, Generalitat de Catalunya.
M.W. and P.R. are staff members of the World Health Organization. These authors alone are responsible for the views expressed in this publication, and they do not necessarily represent the decisions, policy, or views of the World Health Organization.

Dr. Gupta is a postdoctoral fellow at the ISGlobal, Barcelona Centre for International Health Research, Hospital Clínic, Universitat de Barcelona, Barcelona, Spain. His research focus is use of molecular tools for the active surveillance of emerging drug resistance, gene deletions, and afebrile malaria in malaria-endemic regions.

\section{References}

1. O’Meara WP, Mangeni JN, Steketee R, Greenwood B. Changes in the burden of malaria in sub-Saharan Africa. Lancet Infect Dis. 2010;10:545-55. http://dx.doi.org/10.1016/ S1473-3099(10)70096-7

2. World Health Organization. World malaria report 2016 [cited 2017 Mar 24]. http://apps.who.int/iris/bitstre am/10665/252038/1/9789241511711-eng.pdf?ua $=1$

3. Dondorp AM, Nosten F, Yi P, Das D, Phyo AP, Tarning J, et al. Artemisinin resistance in Plasmodium falciparum malaria. N Engl J Med. 2009;361:455-67. http://dx.doi.org/10.1056/ NEJMoa0808859

4. Harrington WE, Mutabingwa TK, Kabyemela E, Fried M, Duffy PE. Intermittent treatment to prevent pregnancy malaria does not confer benefit in an area of widespread drug resistance. Clin Infect Dis. 2011;53:224-30. http://dx.doi.org/10.1093/ $\mathrm{cid} / \mathrm{cir} 376$

5. Hamer DH, Ndhlovu M, Zurovac D, Fox M, Yeboah-Antwi K, Chanda $\mathrm{P}$, et al. Improved diagnostic testing and malaria treatment practices in Zambia. JAMA. 2007;297:2227-31. http://dx.doi.org/ 10.1001/jama.297.20.2227

6. Noedl H, Se Y, Schaecher K, Smith BL, Socheat D, Fukuda MM; Artemisinin Resistance in Cambodia 1 (ARC1) Study Consortium. Evidence of artemisinin-resistant malaria in western Cambodia. N Engl J Med. 2008;359:2619-20. http://dx.doi.org/10.1056/ NEJMc0805011

7. World Health Organization. Artemisinin and artemisinin-based combination therapy resistance. Status report. 2017 [cited 2017 May 5]. http://apps.who.int/iris/bitstream/10665/255213/1/ WHO-HTM-GMP-2017.9-eng.pdf?ua=1

8. Ariey F, Witkowski B, Amaratunga C, Beghain J, Langlois AC, Khim N, et al. A molecular marker of artemisinin-resistant Plasmodium falciparum malaria. Nature. 2014;505:50-5. http://dx.doi.org/10.1038/nature12876

9. Ashley EA, Dhorda M, Fairhurst RM, Amaratunga C, Lim P, Suon S, et al.; Tracking Resistance to Artemisinin Collaboration (TRAC). Spread of artemisinin resistance in Plasmodium falciparum malaria. N Engl J Med. 2014;371:411-23. http://dx.doi.org/10.1056/NEJMoa1314981

10. Witkowski B, Duru V, Khim N, Ross LS, Saintpierre B, Beghain J et al. A surrogate marker of piperaquine-resistant Plasmodium falciparum malaria: a phenotype-genotype association study. Lancet Infect Dis. 2017;17:174-83. http://dx.doi.org/10.1016/S1473-3099(16)30415-7

11. Amato R, Lim P, Miotto O, Amaratunga C, Dek D, Pearson RD et al. Genetic markers associated with dihydroartemisininpiperaquine failure in Plasmodium falciparum malaria in Cambodia: a genotype-phenotype association study. Lancet Infect Dis. 2017;17:164-73. http://dx.doi.org/10.1016/ S1473-3099(16)30409-1 
12. Dhingra SK, Redhi D, Combrinck JM, Yeo T, Okombo J, Henrich PP, et al. A variant PfCRT isoform can contribute to Plasmodium falciparum resistance to the first-line partner drug piperaquine. MBio. 2017;8:e0303-17. http://dx.doi.org/10.1128/ mBio.00303-17

13. Sidhu AB, Uhlemann AC, Valderramos SG, Valderramos JC, Krishna S, Fidock DA. Decreasing $p f m d r 1$ copy number in Plasmodium falciparum malaria heightens susceptibility to mefloquine, lumefantrine, halofantrine, quinine, and artemisinin. J Infect Dis. 2006;194:528-35. http://dx.doi.org/10.1086/ 507115

14. Price RN, Uhlemann AC, Brockman A, McGready R, Ashley E, Phaipun L, et al. Mefloquine resistance in Plasmodium falciparum and increased $p f m d r l$ gene copy number. Lancet. 2004; 364:438-47. http://dx.doi.org/10.1016/S0140-6736(04)16767-6

15. Lim P, Alker AP, Khim N, Shah NK, Incardona S, Doung S, et al. Pfmdr1 copy number and arteminisin derivatives combination therapy failure in falciparum malaria in Cambodia. Malar J. 2009;8:11. http://dx.doi.org/10.1186/1475-2875-8-11

16. Price RN, Cassar C, Brockman A, Duraisingh M, van Vugt M, White NJ, et al. The $p f m d r l$ gene is associated with a multidrugresistant phenotype in Plasmodium falciparum from the western border of Thailand. Antimicrob Agents Chemother. 1999;43:2943-9.

17. Wilson CM, Volkman SK, Thaithong S, Martin RK, Kyle DE, Milhous WK, et al. Amplification of pfmdr 1 associated with mefloquine and halofantrine resistance in Plasmodium falciparum from Thailand. Mol Biochem Parasitol. 1993;57:151-60. http://dx.doi.org/10.1016/0166-6851(93)90252-S

18. Gil JP, Krishna S. pfmdrl (Plasmodium falciparum multidrug drug resistance gene 1): a pivotal factor in malaria resistance to artemisinin combination therapies. Expert Rev Anti Infect Ther. 2017;15:527-43. http://dx.doi.org/10.1080/14787210. 2017.1313703

19. Kamugisha E, Jing S, Minde M, Kataraihya J, Kongola G, Kironde F, et al. Efficacy of artemether-lumefantrine in treatment of malaria among under-fives and prevalence of drug resistance markers in Igombe-Mwanza, north-western Tanzania. Malar J. 2012;11:58. http://dx.doi.org/10.1186/1475-2875-11-58

20. Dokomajilar C, Nsobya SL, Greenhouse B, Rosenthal PJ, Dorsey G. Selection of Plasmodium falciparum pfmdrl alleles following therapy with artemether-lumefantrine in an area of Uganda where malaria is highly endemic. Antimicrob Agents Chemother. 2006;50:1893-5. http://dx.doi.org/10.1128/ AAC.50.5.1893-1895.2006

21. Duraisingh MT, Cowman AF. Contribution of the $p f m d r l$ gene to antimalarial drug-resistance. Acta Trop. 2005;94:181-90. http://dx.doi.org/10.1016/j.actatropica.2005.04.008

22. Fidock DA, Nomura T, Talley AK, Cooper RA, Dzekunov SM, Ferdig MT, et al. Mutations in the P. falciparum digestive vacuole transmembrane protein PfCRT and evidence for their role in chloroquine resistance. Mol Cell. 2000;6:861-71. http://dx.doi.org/10.1016/S1097-2765(05)00077-8

23. Folarin OA, Bustamante C, Gbotosho GO, Sowunmi A, Zalis MG, Oduola AM, et al. In vitro amodiaquine resistance and its association with mutations in $p f c r t$ and $p f m d r l$ genes of Plasmodium falciparum isolates from Nigeria. Acta Trop. 2011; 120:224-30. http://dx.doi.org/10.1016/j.actatropica.2011.08.013

24. Sá JM, Twu O, Hayton K, Reyes S, Fay MP, Ringwald P, et al. Geographic patterns of Plasmodium falciparum drug resistance distinguished by differential responses to amodiaquine and chloroquine. Proc Natl Acad Sci U S A. 2009;106:18883-9. http://dx.doi.org/10.1073/pnas.0911317106

25. Sisowath C, Petersen I, Veiga MI, Mårtensson A, Premji Z, Björkman A, et al. In vivo selection of Plasmodium falciparum parasites carrying the chloroquine-susceptible $p f c r t \mathrm{~K} 76$ allele after treatment with artemether-lumefantrine in Africa. J Infect Dis. 2009;199:750-7. http://dx.doi.org/10.1086/596738

26. Miotto O, Amato R, Ashley EA, MacInnis B, Almagro-Garcia J, Amaratunga $\mathrm{C}$, et al. Genetic architecture of artemisinin-resistant Plasmodium falciparum. Nat Genet. 2015;47:226-34. http://dx.doi.org/10.1038/ng.3189

27. Kublin JG, Dzinjalamala FK, Kamwendo DD, Malkin EM, Cortese JF, Martino LM, et al. Molecular markers for failure of sulfadoxine-pyrimethamine and chlorproguanil-dapsone treatment of Plasmodium falciparum malaria. J Infect Dis. 2002;185:380-8. http://dx.doi.org/10.1086/338566

28. World Health Organization. Policy recommendation on intermittent preventive treatment during infancy with sulfadoxinepyrimethamine (SP-IPTi) for Plasmodium falciparum malaria control in Africa. Geneva: The Organization. p. 1-3.

29. Petersen I, Eastman R, Lanzer M. Drug-resistant malaria: molecular mechanisms and implications for public health. FEBS Lett. 2011;585:1551-62. http://dx.doi.org/10.1016/ j.febslet.2011.04.042

30. Hastings IM, Watkins WM. Intensity of malaria transmission and the evolution of drug resistance. Acta Trop. 2005;94:218-29. http://dx.doi.org/10.1016/j.actatropica.2005.04.003

31. Kwiatkowski DP. How malaria has affected the human genome and what human genetics can teach us about malaria. Am J Hum Genet. 2005;77:171-92. http://dx.doi.org/10.1086/432519

32. Ataide R, Ashley EA, Powell R, Chan JA, Malloy MJ, O'Flaherty K, et al. Host immunity to Plasmodium falciparum and the assessment of emerging artemisinin resistance in a multinational cohort. Proc Natl Acad Sci U S A. 2017; 114:3515-20. http://dx.doi.org/10.1073/pnas.1615875114

33. Enosse S, Magnussen P, Abacassamo F, Gómez-Olivé X, Rønn AM, Thompson R, et al. Rapid increase of Plasmodium falciparum dhfr/dhps resistant haplotypes, after the adoption of sulfadoxine-pyrimethamine as first line treatment in 2002, in southern Mozambique. Malar J. 2008;7:115. http://dx.doi.org/ 10.1186/1475-2875-7-115

34. Raman J, Mauff K, Muianga P, Mussa A, Maharaj R, Barnes KI. Five years of antimalarial resistance marker surveillance in Gaza Province, Mozambique, following artemisinin-based combination therapy roll out. PLoS One. 2011;6:e25992. http://dx.doi.org/10.1371/journal.pone.0025992

35. Galatas B, Nhamussua L, Candrinho B, Mabote L, Cisteró P, Gupta H, et al. In-vivo efficacy of chloroquine to clear asymptomatic infections in Mozambican adults: a randomized, placebo-controlled trial with implications for elimination strategies. Sci Rep. 2017;7:1356. http://dx.doi.org/10.1038/ s41598-017-01365-4

36. Mayor A, Serra-Casas E, Bardají A, Sanz S, Puyol L, Cisteró P, et al. Sub-microscopic infections and long-term recrudescence of Plasmodium falciparum in Mozambican pregnant women. Malar J. 2009;8:9. http://dx.doi.org/10.1186/1475-2875-8-9

37. Taylor SM, Mayor A, Mombo-Ngoma G, Kenguele HM, Ouédraogo S, Ndam NT, et al. A quality control program within a clinical trial consortium for PCR protocols to detect Plasmodium species. J Clin Microbiol. 2014;52:2144-9. http://dx.doi.org/10.1128/JCM.00565-14

38. Ménard D, Khim N, Beghain J, Adegnika AA, Shafiul-Alam M, Amodu O, et al.; KARMA Consortium. A worldwide map of Plasmodium falciparum K13-propeller polymorphisms. N Engl J Med. 2016;374:2453-64. http://dx.doi.org/10.1056/ NEJMoa1513137

39. Salvador C, Rafael B, Matsinhe F, Candrinho B, Muthemba R, De Carvalho E, et al. Efficacy and safety of artemetherlumefantrine for the treatment of uncomplicated falciparum malaria at sentinel sites in Mozambique, 2015. Acta Trop. 2017;171:14650. http://dx.doi.org/10.1016/j.actatropica.2017.03.032 
40. Kamau E, Campino S, Amenga-Etego L, Drury E, Ishengoma D, Johnson K, et al. K13-propeller polymorphisms in Plasmodium falciparum parasites from sub-Saharan Africa. J Infect Dis. 2015;211:1352-5.

41. Andriantsoanirina V, Ratsimbasoa A, Bouchier C, Jahevitra M, Rabearimanana S, Radrianjafy R, et al. Plasmodium falciparum drug resistance in Madagascar: facing the spread of unusual $p f d h f r$ and $p f m d r-1$ haplotypes and the decrease of dihydroartemisinin susceptibility. Antimicrob Agents Chemother. 2009;53:4588-97. http://dx.doi.org/10.1128/AAC.00610-09

42. Leang R, Taylor WR, Bouth DM, Song L, Tarning J, Char MC, et al. Evidence of Plasmodium falciparum malaria multidrug resistance to artemisinin and piperaquine in western Cambodia: dihydroartemisinin-piperaquine open-label multicenter clinical assessment. Antimicrob Agents Chemother. 2015;59:4719-26. http://dx.doi.org/10.1128/AAC.00835-15

43. Phuc BQ, Rasmussen C, Duong TT, Dong LT, Loi MA, Ménard D, et al. Treatment failure of dihydroartemisinin/ piperaquine for Plasmodium falciparum malaria, Vietnam. Emerg Infect Dis. 2017;23:715-7. http://dx.doi.org/10.3201/ eid2304.161872

44. Denis MB, Tsuyuoka R, Poravuth Y, Narann TS, Seila S, Lim C, et al. Surveillance of the efficacy of artesunate and mefloquine combination for the treatment of uncomplicated falciparum malaria in Cambodia. Trop Med Int Health. 2006;11:1360-6. http://dx.doi.org/10.1111/j.1365-3156.2006.01690.x

45. Leang R, Barrette A, Bouth DM, Menard D, Abdur R, Duong S, et al. Efficacy of dihydroartemisinin-piperaquine for treatment of uncomplicated Plasmodium falciparum and Plasmodium vivax in Cambodia, 2008 to 2010. Antimicrob
Agents Chemother. 2013;57:818-26. http://dx.doi.org/10.1128/ AAC.00686-12

46. Amaratunga C, Lim P, Suon S, Sreng S, Mao S, Sopha C, et al. Dihydroartemisinin-piperaquine resistance in Plasmodium falciparum malaria in Cambodia: a multisite prospective cohort study. Lancet Infect Dis. 2016;16:357-65. http://dx.doi.org/ 10.1016/S1473-3099(15)00487-9

47. Chaorattanakawee S, Lon C, Jongsakul K, Gawee J, Sok S, Sundrakes S, et al. Ex vivo piperaquine resistance developed rapidly in Plasmodium falciparum isolates in northern Cambodia compared to Thailand. Malar J. 2016;15:519. http://dx.doi.org/10.1186/s12936-016-1569-y

48. Escobar C, Pateira S, Lobo E, Lobo L, Teodosio R, Dias F, et al. Polymorphisms in Plasmodium falciparum K13-propeller in Angola and Mozambique after the introduction of the ACTs. PLoS One. 2015;10:e119215. http://dx.doi.org/10.1371/ journal.pone. 0119215

49. World Health Organization. Status report on artemisinin and ACT resistance. 2015 [cited 2017 Mar 20]. http://www.who.int/malaria/ publications/atoz/status-rep-artemisinin-resistance-sept2015.pdf

50. Isozumi R, Uemura H, Kimata I, Ichinose Y, Logedi J, Omar AH, et al. Novel mutations in K13 propeller gene of artemisininresistant Plasmodium falciparum. Emerg Infect Dis. 2015;21: 490-2. http://dx.doi.org/10.3201/eid2103.140898

Address for correspondence: Alfredo Mayor, ISGlobal, Barcelona Ctr. Int. Health Res. (CRESIB), Hospital Clínic, Universitat de Barcelona, Carrer Rosselló 153 (CEK Bldg), E-08036 Barcelona, Spain; email: alfredo.mayor@isglobal.org

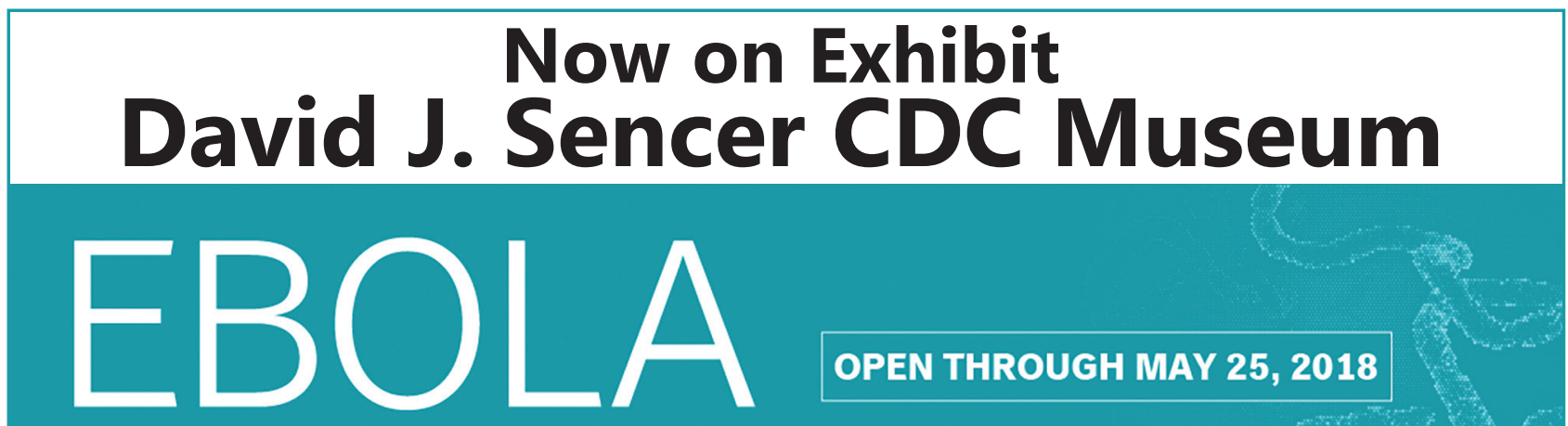

People + Public Health + Political Will

EBOLA: People + Public Health + Political Will is an investigation of the historic 2014-16 Ebola Fever Virus epidemic in West Africa, the United States, and around the world. As the crisis unfolded in Guinea, Liberia, and Sierra Leone in 2014, it evolved into both a health and humanitarian crisis. When it became clear that Ebola could potentially spread exponentially, threatening global health security, there was a coordinated, massive response.

\section{Hours}

Monday: 9 a.m. -5 p.m.

Tuesday: 9 a.m. -5 p.m.

Wednesday: 9 a.m. -5 p.m.

Thursday: 9 a.m. -7 p.m.

Friday: 9 a.m. -5 p.m.

Closed weekends and federal holidays
Location

1600 Clifton Road NE

Atlanta, GA 30329

Phone 404-639-0830

Admission and parking free

Government-issued photo ID required

for adults over the age of 18

Free admission 